\title{
Determining residents' enjoyment of Cantonese opera as their performing arts heritage in Macao
}

\author{
Man-U. Io \& Daniel Chong \\ To cite this article: Man-U. Io \& Daniel Chong (2020): Determining residents' enjoyment of Cantonese opera as their \\ performing arts heritage in Macao, Annals of Leisure Research, DOI: 10.1080/11745398.2020.1804416 \\ To link to this article: https://doi.org/10.1080/11745398.2020.1804416
}

\begin{abstract}
This study attempts to empirically investigate Macao residents' perception and enjoyment of their traditional performing arts - Cantonese opera. By examining the relationship between the experiential attributes and intrinsic artistic components of Cantonese opera, this study found that the experiential attributes and intrinsic craftsmanship were significantly correlate and influence on the residents' enjoyment of their traditional performing arts. While the constructs of "identity connection" and "leisure experiential benefits" are found to have significant prediction towards the intrinsic craftsmanship and residents' enjoyment of Cantonese opera, the intrinsic craftsmanship is the strongest latent variable to predict residents' enjoyment. Moreover, the statistical results reveal that Macao residents' consumption experience of Cantonese opera vary with their socio-demographic characteristics, particularly the residents' birthplace and age. This study empirically supports that the experiential attributes associated with tangible cultural heritage can apply to intangible cultural heritage and influence its attractiveness. Some practical and theoretical implications are suggested.
\end{abstract}

Key words: performing arts heritage, experiential attributes, intrinsic attributes, Cantonese residents, consumption experience 


\section{Introduction}

In recent years, intangible cultural heritage as a tourism product has received much scholarly attention (Ahmad 2006, Butler 2006, Park 2011). In particular, traditional performing arts promote the cultural identity and values of a destination (Henke 2005, Diettrich 2015). Heritage tourism not only boosts the economic values of traditional performing arts, but also arouses awareness towards cultural heritage preservation and sustainable tourism development (Santa-Cruz 2016).

For local community, traditional performing arts reflects their cultural identity, pride, tradition, and history (Connell and Gibson 2004, Hoeven 2012). However, along with the global modernization and the consecutive development of modern performing arts, people are gradually losing their interest in traditional performing arts. The fading of interests and originality have resulted in an urgent need for preservation (UNESCO 2003). Though there are always some loyal fans, the support from the general population is much needed in preserving the popularity and sustainable sustaining the development of traditional performing arts (UNESCO 2003, Bergadaà and Lorey 2015, Miichi 2016). Besides, the supports from the locals not only help to promote their traditional performing arts but also to improve international audiences' receptions (Tikkanen 2008, Diettrich 2015, Palma, Palma et al. 2017).

Cantonese opera, originated in the Guangdong province of China, has been regarded as one of the traditional performing arts of the Cantonese community in Macao (Macau Cultural Affairs Bureau 2016). Macao is situated near east and south of Zhuhai, a city within the Guangdong province, with $87.5 \%$ of the Macao population that speak Cantonese (World population review 2020). Cantonese opera is popular among the Guangdong province including Guangxi, Macao, Hong Kong, and the Chinese communities in Southeast Asia. Similar to other genres of traditional Chinese opera, Cantonese opera combines traditional Cantonese music, singing, martial arts, acrobatics, and acting. In 2009, Macao, Hong Kong, and 
Guangdong province of China applied for the inscription of Cantonese opera on the UNESCO representative list of the intangible cultural heritage of humanity (UNESCO 2009).

Macao was the place where Cantonese opera had its golden era of development in the mid-20 century. Many famous Cantonese opera celebrities such as Yam Kim Fai \& Pak Suet Sin have staged regular performances in Macao. Since then, many have considered Cantonese opera as the most popular genre of performing arts of Macao in the last century (Zhang 2010). Even though that the popularity of Cantonese opera in Macao is gradually decreasing, yet there are still many loyal fans and over 200 performing groups of Cantonese opera remain active in Macao (Io 2018). In addition to its regular performances, Cantonese opera is always featured on TV, radio, Internet, and some local festivals in Macao. Although some teenager-oriented Cantonese opera classes have been introduced to cultivate more younger Cantonese opera fans and artists, however the majority of local audiences are still the older residents. The decrease in younger fans of Cantonese opera is challenging the sustainability of Cantonese opera in Macao (Io 2018).

In view of the importance of understanding the challenges that Cantonese opera is currently facing and developing possible ways to improve its popularity, this study attempts to investigate Cantonese residents' perception of Cantonese opera from the sociocultural perspective. In particular, the study measured the attractiveness of Cantonese opera via a set of experiential attributes and intrinsic artistic components (Io 2019). Similar to tangible cultural heritage, performing arts heritage also provides audiences with a number of experiential benefits, such as cultural, educational, nostalgic, leisure and entertainment experiences (Connell and Gibson 2004, Brandellero, Janssen et al. 2014, Lee and Wong 2017). However, these experiential benefits with respect to the intrinsic craftsmanship of performing arts heritage are seldom being understudied, leaving little understanding of the relationship between the intrinsic craftsmanship, audiences' experiences and their enjoyment of the performing arts. The 
investigation of their relationship helps to explain how local residents' perception and their experiences of traditional performing arts could influence their consumption preference and enjoyment. Theoretical and managerial implications are discussed with the findings in this study.

\section{Literature review}

\section{Cultural significance}

Audience demand for traditional performing arts can be determined by a number of marketing factors, such as ticket price, stage performance quality, and venue facilities (Lee, Yim et al. 2016, Yi and Colbert 2018, Wu, Jiang et al. 2019), but the attractiveness of performing arts heritage relies on its intrinsic and experiential attributes, such as the craftsmanship, entertainment, and cultural experiences (Matheson 2008, Lim and Bendle 2012, Chaney 2017, Kruger and Saayman 2018, Io 2019). The cultural characteristics of various performing arts heritage are important experiential attributes that provide audiences with authentic and unique cultural experiences (Barbieri and Mahoney 2010, Kim, Chung et al. 2018). The rich cultural characteristics of performing arts heritage are the results of tradition, history, and cultural identity of a place and its people (Connell and Gibson 2004, Hoeven 2012, Brandellero, Janssen et al. 2014). In relation to that, Cantonese opera is well recognized as the cultural symbol of the Cantonese community (Macau Cultural Affairs Bureau 2016), because it connects Cantonese audiences to their Cantonese culture, identity, and tradition.

Since the introduction of Cantonese opera in Guangdong province of China 300 hundred years ago, Cantonese opera has gradually becoming a popular genre of performing arts among the Cantonese community. Today, many opera fans enjoy watching and practicing Cantonese opera as a leisure activity and an entertainment in their daily lives (Lin and Dong 2018). Similarly, these activities are commonly 
noticeable in parks and open areas in Macao. Cantonese community of Macao has contributed much to the development of Cantonese opera and has accommodated many famous Cantonese opera performing groups from Hong Kong and Guangdong Province during the $2^{\text {nd }}$ World War (Zhang 2010). With the love for Cantonese opera, many pop Cantonese songs under the inspiration of Cantonese opera were created and became a new form of musical heritage among today's Cantonese population (Lee and Wong 2017). Moreover, Cantonese opera is performed in Cantonese and adopting some Cantonese slangs or idioms which are familiar to the Cantonese speakers (Macau Cultural Affairs Bureau 2016). All these characteristics and history of Cantonese opera are well connected with the Macao's Cantonese population and representing the Cantonese culture in Macao.

The supports among the Cantonese to Cantonese opera would help to pass on this craft to the next generations by maintaining and transmitting their Cantonese culture and values to different parts of the world through tourism (Matheson 2008, Fremaux and Fremaux 2013). In fact, promoting traditional performing arts to tourists is widely encouraged in China. Generally, residents of China are proud of their culture and eager to present it to the tourists through tourism activities which they are benefited both economically and emotionally. (Zheng, Ritchie et al. 2019).

Given the rich cultural elements of Cantonese opera, it is believed that the cultural significance of Cantonese opera is a key factor to attract audiences and influence their consumption experience of Cantonese opera. Therefore, we propose a hypothesis as:

H1: cultural significance has a significant impact on local audiences' appreciation and enjoyment of Cantonese opera. 


\section{Cultural heritage and identity}

Cultural identity is a popular term used in the discussion of cultural heritage and indicating the cultural connection between the place and its heritage (Soper 2007, Goulding and Domic 2009). In the visit to a destination, visitors tried to find similarities between themselves and the place by comparing their own cultural identity with that of the place and develop a sense of belonging and emotional attachment to the place (Maruyama, weber et al. 2010). Personal identity with the place is negotiable and influenced by interpersonal relationship in the place (Bardhia, Ostbergb et al. 2010, Garrido 2011, Hibbert, Dickinson et al. 2013), whereas cultural identity explains the cognitive and affective connection between the place and one's personal identity (Hwang, Lee et al. 2005, Ramkissoon, Smith et al. 2013). By attending the local events of the place, local residents can enhance their personal identity with the place, and in turn form the emotional bond with their homeland (McClinchey 2008, Zhang, Fong et al. 2019). In this sense, local cultural events can provide attendees with a sense of belonging when their cultural identities are connected. Miichi (2016) suggests that the identity connection between people and their traditional performing arts can serve as a form of relief to aid their depression caused by natural disasters.

The cultural identity of heritage products communicates the cultural significance of a place and its people, and thus the cultural identity is regarded as a key component of heritage products in attracting tourists (Goulding and Domic 2009, Santa-Cruz 2016). A long lasting and attractive traditional festivals are believed to be well supported by continuity of local celebration and promotion of their values, ideologies and identity (Zhang, Fong et al. 2019). Cultural identity is also used in the reproduction of heritage such as reenactment events which present the authenticity, identity, and meaning of the heritage to attendees (Carnegie and McCabe 2008, Goulding and Domic 2009). Given the importance of cultural identity for the place and its heritage products, cultural identity is often studied with one's motivation of visiting heritage sites and attending cultural events of the place (Zhang, Fong et al. 2019), as well as with 
one's satisfaction with the place and its heritage attractions and cultural events (Hwang, Lee et al. 2005, Ramkissoon, Smith et al. 2013). The identity connection between visitors and the destination lead visitors to different levels of place identity which in turn determines visitors' experiences and satisfaction with the place (Budruk and Stanis 2013, Ramkissoon, Smith et al. 2013). Place identity reflects visitors' emotional attachment to the destination and can be influenced by their involvement with the place (Gross and Brown 2006, Gross and Brown 2008).

In the literature of performing arts heritage, cultural identity is used to define the genre of performing arts with respect to its home territory (Henke 2005, Patkin 2015). The cultural identity of a particular region travels across different geographical distances through local musicians and audiences to facilitate the global flow of culture (Connell and Gibson 2004, Butler 2006). Some ethnic groups are easily attracted to their traditional music wherever they are living in due to their identity connection with the music (Brandellero, Janssen et al. 2014, Hoeven and Brandellero 2015). Similarly, Cantonese opera travels from one place to another and attracts many Cantonese audiences due to its connection with the Cantonese identity. Therefore, identity connection is likely to make Cantonese opera more attractive to Cantonese people than foreigners.

Besides, the cultural connection between people and their own heritage is considered to motivate them to consume their own cultural heritage. For example, Zhao \& Timothy's study (2017) indicates that many Chinese people enjoy taking a communist heritage tour in mainland China because the tour allows them to recall their collective memory about the Chinese Communist Party. Typically, the emotional connection was triggered by activities such as visiting the sites related to the history of the Chinese Communist Party and singing the communist songs. Similarly, Macao residents who appreciate and participate much in the local cultural festivals are found to be more committed to their national identity (Zhang, Fong et al. 2019). Therefore, as a cultural symbol of Cantonese people, Cantonese opera has a 
deep connection with Cantonese audiences' personal identity, and such identity connection may enhance Cantonese audiences' emotional bond with Cantonese opera. This may lead them to consume and enjoy this genre of performing arts more. This leads to the hypothesis as:

H2: identity connection has a significant impact on local audiences' appreciation and enjoyment of Cantonese opera.

\section{Experiential benefits}

Traditional performing arts of the place provide many experiential benefits for foreign audiences, such as learning about the local arts and culture, a sense of authenticity, social interaction, cultural experience and entertainment (Kim, Chung et al. 2018, Kruger and Saayman 2018). Local residents also gain many experiential benefits related to their leisure life from the local performing arts such as entertainment, excitement, socialization, novelty, and music enjoyment (Henke 2005, Matheson 2008, Vinnicombe and Sou 2017). To improve the entertainment experience for the local and foreign audiences, general performing arts work very hard on the production quality of stage performance. The performance qualities includes innovativeness (use of new technology and engineering advances), design (appearance, style, color, variety), prestige (exclusivity, status, brand name reputation), and workmanship (reliability, durability, craftsmanship, manufacturing quality) (Roth and Romeo 1992, Lim and Bendle 2012).

The performance quality of performing arts is particularly important for audiences' satisfaction and entertainment experiences (Jobst and Boerner 2011, Lim and Bendle 2012, Lee, Yim et al. 2016). Many Cantonese opera performing groups in Macao have invested much in uplifting the quality of their costume and craftsmanship as their commitment to performance quality (Io 2018). In addition to entertainment, performing arts offer other experiential benefits related to socialization. For example, jazz and hip-hop music originated in U.S.A are well-accepted by the locals because of its entertaining and 
socio-cultural values (Xie, Osumare et al. 2007, Kruger and Saayman 2018). Likewise, Cantonese opera enriches the leisure and cultural life of Cantonese opera fans. For instance, greater social bonding can be created among opera fans through group learning and practices. (Butler 2006, Kim, Chung et al. 2018, Lin and Dong 2018, Io 2019).

The wide recognition of the experiential benefits from a performing art enhances the attractiveness of the craft and in turn stimulates a high demand (both local and international audiences) and supply (increasing fans base and frequencies of performances) (Lee and Wong 2017, Palma, Palma et al. 2017). Different from foreign audiences, local residents patronize their traditional performing arts because of the leisure value rather than the authentic and exotic experiences sought by foreign audiences (Henke 2005, Matheson 2008, Tikkanen 2008). For residents, traditional performing arts particularly offer them a range of leisure experiential benefits such as entertainment, cultural experience, educational benefits, and socialization (Vinnicombe and Sou 2017, Lin and Dong 2018). Therefore, it is believed that the experiences provided by Cantonese opera benefit residents' leisure life and may determine local audiences' consumption preference and enjoyment. This leads to the hypothesis as:

H3: leisure experiential benefits have a significant impact on local audiences' appreciation and enjoyment of Cantonese opera.

In addition to the leisure experiential benefits aforementioned, the craftsmanship as the intrinsic artistic component of performing arts is much related to the attractiveness of each genre of performing arts and influential on audiences' consumption experience (Brandellero, Janssen et al. 2014, Lee, Yim et al. 2016, Io 2019). In the case of Cantonese opera, its intrinsic craftsmanship refers to its inner artistic components such as its music and acting style, stage costume \& make-up (Zhang 2010, Macau Cultural Affairs Bureau 2016, Io 2019). Cantonese opera shows its intrinsic characteristics in its vibrant 
performance style which combines dance, drama, martial arts, music, singing and verse, colorful costume, make-up, and intricate gesture (Macau Cultural Affairs Bureau 2016). All these intrinsic components shape the performing style of Cantonese opera and differentiate it from other genres of performing arts (UNESCO 2009).

Similar to other genres of performing arts heritage, it takes time for the craftsmanship of Cantonese opera to be fully appreciated and enjoyed, particularly the foreigners. Previous studies suggest that local people may enjoy their own musical heritage more than foreigners because of their understanding and appreciation towards the craftsmanship of their own musical heritage (Matheson 2008, Bergadaà and Lorey 2015, Lee and Wong 2017). Therefore, audiences' understanding and appreciation of the craftsmanship of Cantonese opera may positively influence their enjoyment of the craft. This leads to a hypothesis as:

H4: local audience' appreciation of the craftsmanship attributes has a significant impact on their enjoyment of Cantonese opera.

\section{Methods}

Variables and Measurement

A quantitative survey was conducted to collect the local audiences' demographic information and consumption experience of with Cantonese opera in Macao. To measure audiences' perception of Cantonese opera, several variables were extracted from the literature and were included in the survey questionnaire. There are five constructs conceptualized and extracted from the literature for measuring the attributes of performing arts heritage which includes cultural significance, identity connection, leisure experiential benefits, enjoyment, and craftsmanship. The construct of cultural significance covers six 
variables extracted from the heritage literature of performing arts and adjusted to reflect the cultural characteristics of Cantonese opera (Matheson 2008, Li 2012, Lee and Wong 2017, Io 2018).

The measurement of identity connection covers three variables extracted from the studies of place identity (Kil, Holland et al. 2012, Ramkissoon, Smith et al. 2013, Zhang, Fong et al. 2019). The construct of leisure experiential benefits include five variables about the leisure values and experiences such as entertainment, education, and cultural life for residents (Chen 2011, Pavluković, Armenski et al. 2017, Vinnicombe and Sou 2017). The enjoyment of performing arts heritage is operationally defined as audiences' consumption habit and positive feelings of Cantonese opera. Hence, it was measured by three variables reflecting audiences' positive feelings and consumption habit of Cantonese opera performance and events (Huh, Uysal et al. 2006, Schofield and Thompson 2007, Rojas and Camarero 2008). The craftsmanship of Cantonese opera were measured by four variables extracted from the governmental official description of Cantonese opera which covers all noticeable artistic characteristics of Cantonese opera, including drama, verses, music \& dance, and costume \& make-up (UNESCO 2009, Zhang 2010, Macau Cultural Affairs Bureau 2016). All the variables of the five constructs: cultural significance, identity connection, leisure experiential benefits, enjoyment, and craftsmanship, were presented by written statements and measured by a 5-point Likert scale with anchors $1=$ strongly disagree to $5=$ strongly agree. For example, to measure respondents' perception of craftsmanship attributes, one of the statements is written in Chinese and translated to English as "the music and dance as a whole are artistic".

Before the survey, the questionnaire was evaluated by using a Pilot test, in which the questionnaires were delivered to 20 Cantonese-opera audiences at the entrance of a local theater where the live performances of Cantonese opera are always held. The pilot test aimed to confirm the clarity of the questionnaire to the residents. According to the feedbacks from the respondents, some variables shared 
similar meanings, and hence some statements were revised to improve its clarity, and the finalized survey questionnaire was written in Chinese.

\section{Sample and data collection}

The survey population was confined with only Cantonese speakers who were familiar with Cantonese opera and currently living in Macao. To find qualified respondents, we chose three locations where Cantonese opera performances were often held, including the area near the theatre for staging Cantonese opera and two public parks where Cantonese opera fans often practice Cantonese opera as their leisure activity. Moreover, only residents who had watched the live performance of Cantonese opera staged in the theatres or local cultural events and festivals in the past 12 months were selected for the survey to ensure their familiarity towards Cantonese opera. There are over 200 performing groups of Cantonese opera in Macao, staging Cantonese opera for local residents year round in the theatres and some local cultural events and festivals, (Macao Government Tourist Office 2017).

The survey schedule was designed to maximize the opportunity of meeting more local audiences of Cantonese opera, and hence it was conducted in a week of July 2018, from Friday to Sunday, 10:00 12:00 and 16:30 - 18:30. Survey assistants, aged from 20 to 22 , were recruited from a local tertiary institute of Macao and were trained to conduct the survey. Survey assistants worked together in pairs at each location, and total of three pairs of assistants conducted the survey at three locations simultaneously. The survey was designed as a self-administered questionnaire and structured with closed-ended questions which require respondents to select from a predetermined set of responses or scale points. Survey assistants stood at the busy area and approached respondents that were passing by randomly. After getting respondents' consent and confirming that they had watched Cantonese opera in the past 12 months, survey 
assistants offered each respondent a copy of questionnaire to fill in. The instruction and further explanation were given to those respondents who need further clarifications. The survey ended with 300 completed questionnaires excluding minors and incomplete forms.

\section{Results}

As shown in Table 1, total 300 Macao residents have responded. Their profile reveals $62.3 \%$ of respondents were born in Macao or Hong Kong, 34.3\% of respondents were born in Guangdong province of mainland China, while $3.3 \%$ of respondents were born in non-Guangdong province. Besides, $96 \%$ of respondents have been living in Macao for 10 years and above. 63.6\% of respondents have at least a Cantonese opera fan who always watches Cantonese opera on TV, online, or in theatres in their family which includes the household members living in Macao. This finding suggests that $63.6 \%$ of respondents generally have more chances to notice Cantonese opera in their family. Similar to the proportion of elderly residents in Macao that carries about 20\% of the Macao population (Statistics and Census Bureau 2016), respondents over 65 years old make up the smallest proportion by carrying $19.7 \%$ of the survey sample. Moreover, female respondents (54\%) are more than male respondents $(46 \%)$ in the survey sample, comparable to that in Macao population that female residents are more than male residents (Statistics and Census Bureau 2016). Respondents who have finished high school (28.7\%) and tertiary education (39\%) make up the largest proportion of the sample. Regarding employment, respondents who are retired or doing part-time jobs is the largest group of the sample and may have more time for leisure activities.

<please insert table 1 here>

Regarding respondents' experience of Cantonese opera, the ANOVA analysis results shown in Table 2 reveal that respondents at age $50-65(\mathrm{M}=3.8$ out of 5$)$ and above 65 years old $(\mathrm{M}=4.05$ out of 5) appreciate the craftsmanship attributes of Cantonese opera much more than those respondents at age 
$18-49(\mathrm{M}=2.37-2.78)$. Moreover, respondents at age 50 and above have higher mean values than younger respondents for all other attribute constructs, including the craftsmanship $(\mathrm{M}=3.8-4.05)$, cultural significance $(M=4.24-4.30)$, identity connection $(M=3.78-3.99)$, leisure experiential benefits $(\mathrm{M}=3.82-3.93)$, and enjoyment $(\mathrm{M}=3.73-3.93)$ of Cantonese opera. Respondents who were born in Guangdong province are found to have the highest mean values for all attribute constructs of Cantonese opera and perceive them significantly more positive than those who were born in Macao/Hong Kong and non-Guangdong province of mainland China. Furthermore, respondents with primary-school educational level have the highest mean values for all the attribute constructs of Cantonese opera among all educational categories.

To gain a better understanding of Cantonese residents' perception and enjoyment of Cantonese opera, four constructs of experiential attributes were generated and tested by confirmatory factor analysis (CFA). CFA is considered an appropriate method for testing the validity of constructs (Browne and Cudeck 1992, Hair, Black et al. 2010). According to the results of CFA (table 3), the overall fitness of the model was tested by common parameters, including Chi-square value and degree of freedom (Cmin/df), goodness-of-fit index (GFI), comparative fit index (CFI), incremental fit index (IFI), and root mean square error of approximation (RMSEA). Moreover, The fitness of the CFA model was improved by performing the trimming procedure as suggested by Voss, Spangenberg, \& Grohmann (2003). By removing the parameters that had the highest $\mathrm{p}$-value $(\mathrm{p}>0.05)$ and items with low loadings, there are five items left to define the construct of cultural significance, two items left to define the construct of identity connection, three items left to define the construct of leisure experiential benefits, and three items remained to define the construct of enjoyment in the adjusted model.

The internal consistency of four experiential constructs and the intrinsic construct - craftsmanship which represents the inner components of Cantonese opera was tested and proved good by revealing that 
all their Cronbach's alphas were greater than .70, exceeding the recommended standard. The adequacy of the CFA model was evidenced by the five indices of goodness of fit (Cmin/df, CFI, GFI, IFI, and RSEMA). $\mathrm{Cmin} / \mathrm{df}=3.12$ was lower than 5 and suggesting the acceptance of the model (Schumacker and Lomax 2004, Ernest and Heriyadi 2008). Other indices: $\mathrm{CFI}=.96, \mathrm{IFI}=.96, \mathrm{GFI}=.92, \mathrm{RSEMA}=.08$ also supported the model fitness (Anderson and Gerbing 1988, Hair, Black et al. 2010). Moreover, the composite reliabilities $(\mathrm{CR}>0.7)$ and average variance extracted $(\mathrm{AVE}>0.5)$ of four constructs of experiential attributes exceeded the threshold and supported the convergent validity and reliabilities.

To understand the relationship between these five constructs, a correlation test has been conducted, and the results shown in Table 4 reveal that all constructs are significantly inter-related. To test on the coeffects of experiential constructs on respondents' appreciation and enjoyment of Cantonese opera, four hypotheses are proposed and tested by using structural equation modelling (SEM), which is often used for analyzing multivariate data and involving complex relationship among variables (Browne and Cudeck 1992, Hair, Black et al. 2010). By using Amos 24 and following the procedure of trimming a model for better fit suggested by Voss, Spangenberg, \& Grohmann (2003), the structural model has been tested and adjusted. As shown in Table 5, the five indices of goodness of fit $(\mathrm{Cmin} / \mathrm{df}=1.94, \mathrm{CFI}=.99, \mathrm{GFI}=.99$, IFI $=.99$, and RSEMA $=.056)$ suggests the fitness of the model. Moreover, the results reveal that all hypotheses are well supported except hypothesis 1 which indicates that cultural significance does not have significant impact on residents' appreciation of the craftsmanship and enjoyment of Cantonese opera. Moreover, respondents' appreciation of the craftsmanship can also positively influence their enjoyment and consumption habit of Cantonese opera. Therefore, the more respondents acknowledge the cultural identity and experiential benefits of Cantonese opera, the more they appreciate and enjoy it. 


\section{Discussion and implications}

With the aim of understanding how the intrinsic and experiential attributes may influence Cantonese residents' enjoyment of Cantonese opera as their performing arts heritage in Macao, this study investigated the Cantonese residents' perception of Cantonese opera with respect to its intrinsic and experiential attributes. The examination of the relationship between these attributes suggested although the respondents are familiar with Cantonese opera, however varied in levels of emotional bonding with their performing arts heritage. The respondents at age 50 and above appreciate and enjoy Cantonese opera more than those in other age groups. These older residents have witnessed the prosperous development period of Cantonese opera during 1970 - 80s when Cantonese opera was as popular as pop music in Macao and Hong Kong (Zhang 2010). Such experience may leave them a deeper collective memory about Cantonese opera and result in higher sense of loyalty towards the performing art. This finding is similar to that in other places where the locals tend to favor their traditional music because of their collective memory and identity with it (Brandellero, Janssen et al. 2014, Hoeven and Brandellero 2015, Lee and Wong 2017). In line with the study of Wu, Jiang et al. (2019) that higher education has a negative impact on the demand of traditional Chinese opera, this study also finds that respondents under 50 years old with tertiary and above education perceive lower identity connection, experiential benefits and appreciation towards craftsmanship of Cantonese opera though they well recognize its cultural significance.

Besides, respondents who were born in Guangdong province of mainland China perceive the experiential and intrinsic attributes of Cantonese opera better than other respondents do. This finding suggests that Guangdong province as the birthplace of Cantonese opera enhances the emotional and cultural bond between Cantonese opera and those respondents who were born in Guangdong province. Similar connection is found in other places where people try to connect with their homeland and cultural identity by listening to their traditional home music (Matheson 2008, Miichi 2016). Moreover, tourists 
enjoy visiting the birthplace of a particular genre of music or performing arts as they recognize the authentic connection between the performing arts and its birthplace (Patkin 2015, Chaney 2017, Wu, Jiang et al. 2019).

The results of hypotheses $2-4$ suggest that the intrinsic and experiential attributes have significant impacts on local audiences' appreciation and enjoyment of Cantonese opera. Therefore, to improve audiences' appreciation of the craftsmanship and positive experience of Cantonese opera, the intrinsic and experiential attributes should be improved and highlighted in the promotion and educational programs of Cantonese opera. The results suggest that the more local audiences could connect and gain experiential benefits from Cantonese opera, the more they could appreciate and enjoy Cantonese opera. Considering younger (age at 18 -49) respondents' moderate weak acknowledgement of these two constructs: identity $(\mathrm{M}=2.64 \& 2.78)$ and experiential benefits $(\mathrm{M}=2.77 \& 2.70)$, more workshops and educational programs targeting them should be arranged to improve their knowledge and cultural connection of Cantonese opera. Cantonese opera practitioners should consider modifying the performance of Cantonese opera to provide younger audiences with more fun elements which could improve their interest in Cantonese opera.

This study also reveals the important role played by the craftsmanship attributes of Cantonese opera in between identity connection, leisure experiential benefits, and enjoyment. The results suggest that the craftsmanship construct (loading weight $=0.49$ ) has a greater impact on the enjoyment construct than the identity connection (loading weight $=0.21$ ) and leisure experiential benefits constructs (loading weight $=0.25)$ do. The constructs of identity connection and leisure experiential benefits have greater impacts on the craftsmanship than the enjoyment. Therefore, the improvement of identity connection and leisure experiential benefits should aim to increase audiences' appreciation of the craftsmanship and in turn improve their enjoyment of Cantonese opera. Moreover, the craftsmanship construct has the greatest impact on audiences' enjoyment of Cantonese opera, and thus educating local audiences about the unique 
and attractive craftsmanship and improving their appreciation of it would help to improve their enjoyment of Cantonese opera. (Bergadaà and Lorey 2015, Diettrich 2015).

This present study takes Cantonese opera as a case study in understanding how residents perceive and consume their own traditional performing arts. The results suggested that audiences' consumption and enjoyment of their own traditional performing arts can be influenced by four important attributes namely cultural significance, leisure experiential benefits, identity connection, and craftsmanship. Though experiential attributes are widely discussed in the context of cultural events and tangible heritage attractions (Carnegie and McCabe 2008, Goulding and Domic 2009), they are rarely and specifically investigated with regards to consumers' enjoyment in the context of performing arts heritage. Some researchers suggest that a genre of music heritage is popular among some people because it represents these people's cultural identity (Hoeven 2012, Brandellero, Janssen et al. 2014, Lee and Wong 2017). However, experiential attributes are not limited to cultural identity, but also to the cultural significance and experiential benefits related to audiences' leisure life in the context of performing arts heritage. This present study examined how these experiential attributes could influence residents' enjoyment of their own performing arts heritage. The results empirically confirmed that the cultural significance, identity connection, and leisure experiential benefits are highly and significantly correlated to the intrinsic craftsmanship attributes and residents' enjoyment of their own music heritage.

Besides, the intrinsic craftsmanship attributes are seldom been studied with the experiential attributes aforementioned in the context of performing arts heritage, though audiences' satisfaction can be influenced by a number of performance attributes, such as performance production quality, performers' professionalism, stage settings, and theatre facilities (Song and Cheung 2010, Jobst and Boerner 2011, Lim and Bendle 2012). By investigating the craftsmanship attributes with respect to the experiential attributes, this present study empirically revealed the mediating role played by the intrinsic attributes 
between the experiential attributes and audiences' enjoyment of their performing arts heritage. Moreover, the significant impacts of experiential and intrinsic attributes on residents' enjoyment of their performing arts heritage have been empirically supported in this study. The results enhance the knowledge of audiences' experience with performing arts as a form of intangible cultural heritage. The intrinsic and experiential attributes should be included in the investigation of other forms of intangible cultural heritage with consumers' satisfaction.

\section{Conclusion and limitations}

This study adds some important values to the literature of performing arts heritage by offering some insights into Macao Cantonese residents' perception and enjoyment of Cantonese opera with respect to its experiential and intrinsic attributes. The results indicated that there are significant effects of identity connection, leisure experiential benefits, and craftsmanship attributes on residents' enjoyment of Cantonese opera. Moreover, this present study contributes to the knowledge of preserving performing arts as a form of intangible cultural heritage by revealing the significant relationship between the intrinsic and experiential attributes of Cantonese opera and their co-effects on audiences' enjoyment. Future research in other forms of intangible cultural heritage should include the intrinsic and experiential attributes in examining their relationship and impacts on consumers' satisfaction.

The empirical findings also provide practical suggestions for improving local residents' consumption experience with Cantonese opera, and in turn gaining more support from the locals to the sustainable development of Cantonese opera. For future research, the hypotheses in this study can serve as a framework for investigating residents' traditional performing arts consumption experience in their own cultural backgrounds. Moreover, more intrinsic attributes of a performing art, such as performance 
production quality, stage settings, and theatre facilities, should be investigated in response to consumers' emotional bonding.

The major limitations are noted. First, marketing factors are not included in this study, though they are always considered important in influencing consumers' experience with performing arts (Lim and Bendle 2012, Lee, Yim et al. 2016). Future studies should examine the impact of marketing mix on residents' consumption experience of their own performing arts heritage. Second, qualitative approach is not used to explore residents' emotional experiences of their performing arts heritage, as this study attempts to test the relationship between the intrinsic and experiential attributes and their effects on audiences' enjoyment. Future research should consider qualitative approach to further investigate audiences' emotional and nostalgic experiences of their performing arts heritage. In addition, to generalize the results of the hypotheses tested in this study, future studies should further test them in other cultural contexts.

\section{Table 1. Repodents' profile}

Variables $(\mathrm{n}=300)$

Frequency

Percentage \%

\section{Place of birth}

Macao/Hong Kong

187

62.3

Guangdong province

103

34.3

Non-Guangdong province

10

3.3

Number of $\mathrm{CO}$ fans in family

0

109

36.3

$1-3$

174

58

$4-6$

$16 \quad 5.3$

$>6$

1

0.3

Length of residence in Macao

$>1$ year

4

1.3

$1-3$ years

0.7

$4-9$ years

2.0

$10-20$ years

13

$>20$ years

249

83 


\section{Gender}

Male

$230 \quad 46$

Female

270

54

Age

$18-29$

102

34

$30-49$

79

26.3

$50-65$

59

19.7

$>65$

60

20

\section{Education}

primary school

77

25.7

high school

86

28.7

tertiary

117

39

post graduate

20

6.7

\section{Employment}

blue collar

$9 \quad 3.0$

white collar

$58 \quad 19.7$

full-time student

56

18.7

professional

43

14.3

employer/executive director

15

5.0

retired/part-timer

119

39.7

Table 2. ANOVA analysis for residents' perception of Cantonese opera by demographic factors

\begin{tabular}{|c|c|c|c|c|}
\hline & $\mathrm{N}$ & Mean & Std. D. & $\mathrm{F}$ \\
\hline Craftsmanship & & & & $50.56 * * *$ \\
\hline $18-29$ & 102 & $2.78 \mathrm{a}$ & 0.92946 & \\
\hline $30-49$ & 79 & $2.37 \mathrm{~b}$ & 0.89829 & \\
\hline Enjoyment & & & & $67.14 * * *$ \\
\hline $18-29$ & 102 & $2.52 \mathrm{a}$ & 0.58645 & \\
\hline $30-49$ & 79 & $2.38 \mathrm{a}$ & 0.52525 & \\
\hline $18-29$ & 102 & $3.51 \mathrm{a}$ & 0.91117 & \\
\hline
\end{tabular}




\begin{tabular}{|c|c|c|c|}
\hline $30-49$ & 79 & $3.48 \mathrm{a}$ & 1.30064 \\
\hline $50-65$ & 59 & $4.24 b$ & 0.95125 \\
\hline$>65$ & 60 & $4.30 \mathrm{~b}$ & 0.83005 \\
\hline$\underline{\text { Identity connection }}$ & & & $52.01 * * *$ \\
\hline $18-29$ & 102 & $2.64 \mathrm{a}$ & \\
\hline $30-49$ & 79 & $2.78 \mathrm{a}$ & \\
\hline $50-65$ & 59 & $3.78 b$ & \\
\hline$>65$ & 60 & $3.99 b$ & \\
\hline Leisure experiential benefits & & & $42.20 * * *$ \\
\hline $18-29$ & 102 & $2.77 \mathrm{a}$ & 0.78244 \\
\hline $30-49$ & 79 & $2.70 \mathrm{a}$ & 0.60760 \\
\hline $50-65$ & 59 & $3.82 \mathrm{~b}$ & 0.57350 \\
\hline$>65$ & 60 & $3.93 b$ & 0.61838 \\
\hline \multicolumn{4}{|l|}{ By birth place } \\
\hline$\underline{\text { Craftsmanship }}$ & & & $22.06 * * *$ \\
\hline Macao/HK & 187 & $2.82 \mathrm{a}$ & 1.03169 \\
\hline Guangdong province & 103 & $3.70 \mathrm{~b}$ & 0.89417 \\
\hline non-Guangdong province & 10 & $2.88 \mathrm{a}$ & 1.27628 \\
\hline Enjoyment & & & $32.43 * * *$ \\
\hline Macao/HK & 187 & $2.65 \mathrm{a}$ & 0.68960 \\
\hline Guangdong province & 103 & $3.61 \mathrm{~b}$ & 0.64441 \\
\hline non-Guangdong province & 10 & $3.33 b$ & 0.68853 \\
\hline Cultural significance & & & $21.73 * * *$ \\
\hline Macao/HK & 187 & $3.61 \mathrm{a}$ & 1.03139 \\
\hline Guangdong province & 103 & $4.17 \mathrm{~b}$ & 0.98750 \\
\hline non-Guangdong province & 10 & $3.66 \mathrm{a}$ & 1.27039 \\
\hline Identity connection & & & $21.66^{* * *}$ \\
\hline Macao/HK & 187 & $2.90 \mathrm{a}$ & 1.03139 \\
\hline Guangdong province & 103 & $3.65 b$ & 0.98750 \\
\hline non-Guangdong province & 10 & $3.35 \mathrm{ab}$ & 1.27039 \\
\hline$\underline{\text { Leisure experiential benefits }}$ & & & $16.36 * * *$ \\
\hline Macao/HK & 187 & $2.95 \mathrm{a}$ & 0.78883 \\
\hline Guangdong province & 103 & $3.62 b$ & 0.62462 \\
\hline non-Guangdong province & 10 & $3.40 \mathrm{ab}$ & 0.82031 \\
\hline \multicolumn{4}{|l|}{ By education } \\
\hline Craftsmanship & & & $22.83 * *$ \\
\hline primary school & 77 & $3.90 \mathrm{~b}$ & 0.83282 \\
\hline high school & 86 & $3.17 \mathrm{a}$ & 1.05292 \\
\hline
\end{tabular}




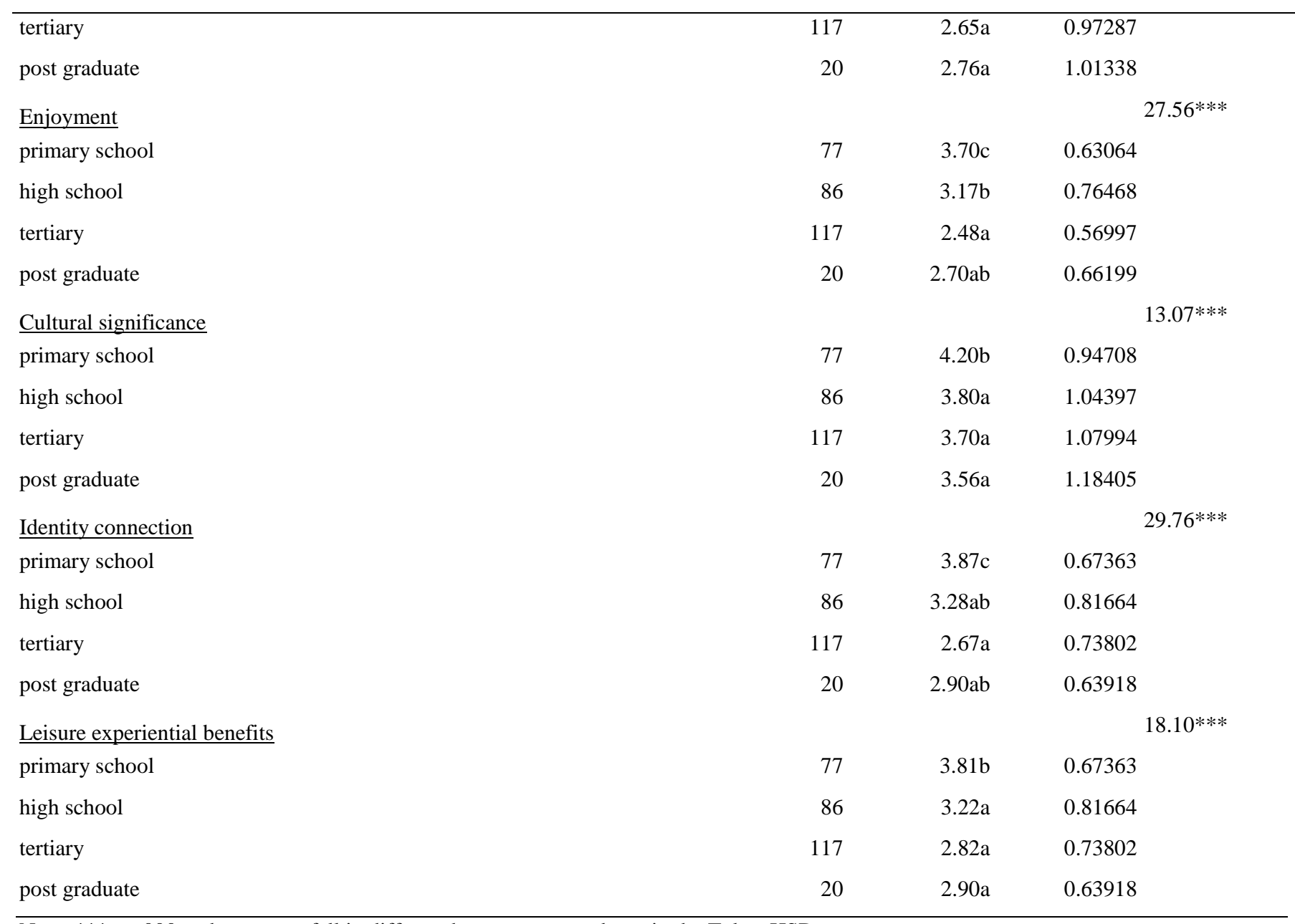

Note: ***p $=.000 ; \mathrm{a}, \mathrm{b}, \mathrm{c}$ means fall in different homogeneous subsets in the Tukey HSD test.

Table 3. CFA results of residents' perception of Cantonese opera (CO)

\begin{tabular}{|c|c|c|c|c|c|c|}
\hline & $\begin{array}{c}\text { factor } \\
\text { loading }\end{array}$ & Mean & $\begin{array}{c}\text { Std. } \\
\text { Deviation }\end{array}$ & $\mathbf{R}^{2}$ & $\mathbf{C R}$ & AVE \\
\hline Cultural significance $($ Cronbach's Alpha $=\mathbf{~ . 8 4})$ & & & & & 0.84 & 0.52 \\
\hline $\mathrm{CO}$ is collective memory & $.82 * * *$ & 3.41 & 1.009 & 0.67 & & \\
\hline $\mathrm{CO}$ reflects the past generations & $.78 * * *$ & 3.70 & 0.966 & 0.62 & & \\
\hline $\mathrm{CO}$ communicates the local culture to foreigners & $.78 * * *$ & 3.65 & 1.101 & 0.61 & & \\
\hline Craftsmanship (Cronbach's Alpha = .96) & & & & & 0.96 & 0.86 \\
\hline the story-telling style is interesting & $0.95 * * *$ & 3.00 & 1.24 & .90 & & \\
\hline the verses are poetic & $0.95 * * *$ & 2.99 & 1.22 & .91 & & \\
\hline
\end{tabular}


the costume and make-up as a whole are traditional and beautiful

$0.86 * * *$

3.39

1.22

0.89

0.74

Alpha $=$.89)

$\mathrm{CO}$ serves as a leisure and entertainment activity for the locals

$\begin{array}{llll}.87 * * * & 3.20 & 1.131 & 0.76 \\ .90 * * * & 3.26 & 1.062 & 0.81 \\ .80 * * * & 3.12 & 1.179 & 0.64\end{array}$

Cantonese culture

(1)

0.90

0.82

CO says a lot about who I am

$\begin{array}{llll}.91 * * * & 3.20 & 1.014 & 0.83 \\ .90^{* * *} & 3.14 & 1.086 & 0.80\end{array}$

$\mathrm{CO}$ is part of me

$.90 * * *$

3.14

0.88

0.71

Enjoyment $($ Cronbach's Alpha $=.85)$

I enjoy watching Cantonese opera

$.97 * * *$

2.80

1.354

0.94

I always watch Cantonese opera

$.94 * * *$

2.50

1.355

0.88

I like the artistic quality of Cantonese opera

$.56 * * *$

3.71

0.884

0.32

Note: $* * * \mathrm{p}=.000, \mathrm{Cmin} / \mathrm{df}=3.12 ; \mathrm{GFI}=.89 ; \mathrm{CFI}=.95 ; \mathrm{IFI}=.95 ; \mathrm{RMSEA}=.08$

Table 4. Constructs Inter-correlations

\begin{tabular}{|c|c|c|c|c|c|c|c|}
\hline & $\begin{array}{l}\text { Cultural } \\
\text { significance }\end{array}$ & $\begin{array}{l}\text { Identity } \\
\text { connection }\end{array}$ & $\begin{array}{l}\text { Leisure } \\
\text { experiential } \\
\text { benefits }\end{array}$ & Enjoyment & Craftsmanship & M & Std. \\
\hline Cultural significance & 1 & & & & & 3.8 & 0.74 \\
\hline Identity connection & $.667^{* *}$ & 1 & & & & 3.2 & 1 \\
\hline Leisure benefits & $.663^{* *}$ & $.684^{* *}$ & 1 & & & 3.2 & 1.02 \\
\hline Enjoyment & $.603^{* *}$ & $.691^{* * *}$ & $.742^{* *}$ & 1 & & 3 & 1.07 \\
\hline Craftsmanship & $.578^{* *}$ & $.631^{* *}$ & $.705^{* *}$ & $.801^{* *}$ & 1 & 3.13 & 1.16 \\
\hline
\end{tabular}

**. Correlation is significant at the 0.01 level (2-tailed).

Table 5. Structural model: standard regression weights

\section{craftsmanship enjoyment}

\section{predictors}

Cultural significance

$0.00 \quad 0.00$

Identity connection

$0.24 * * * \quad 0.21 * * *$

Leisure experiential benefits

$0.47 * * *$

$0.25 * * *$

Craftsmanship (Cronbach's

Alpha = .96)

$$
0.49 * * *
$$

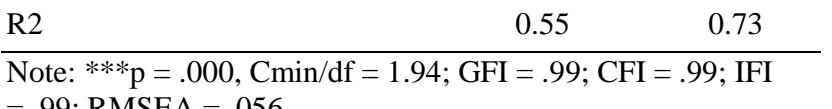

$=.99 ;$ RMSEA $=.056$ 


\section{References}

Ahmad, Y. (2006). "The Scope and Definitions of Heritage: From Tangible to Intangible." International Journal of Heritage Studies 12(3): 292-300.

Anderson, J. C. and D. W. Gerbing (1988). "Structural equation modeling in practice: A review and recommended two-step approach." Psychological Bulletin 103(3): 411-423.

Barbieri, C. and E. Mahoney (2010). "Cultural Tourism Behaviour and Preferences among the Live-performing Arts Audience: an Application of the Univorous-Omnivorous Framework." International Journal of Tourism Research 12: 481-496.

Bardhia, F., et al. (2010). "Negotiating cultural boundaries: Food, travel and consumer identities." Consumption Markets and Culture 13(2): 133-157.

Bergadaà, M. and T. Lorey (2015). "Preservation of Living Cultural Heritage: The Case of Basque Choirs and Their Audience." International Journal of Art Management 17(3): 15.

Brandellero, A., et al. (2014). "Popular music heritage, cultural memory and cultural identity." International Journal of Heritage Studies 20(3): 219-223.

Browne, M. W. and R. Cudeck (1992). "Alternative ways of assessing model fit." Sociological Methods and Research 21(2): 230-258.

Budruk, M. and S. A. W. Stanis (2013). "Place attachment and recreation experience preference: A further exploration of the relationship." Journal of Outdoor Recreation and Tourism 1(2): 51-61.

Butler, R. W. (2006). "Music and Tourism: On the Road Again." Annals of Tourism Research 33(2): 583-585.

Carnegie, E. and S. McCabe (2008). "Re-enactment events and tourism: meaning, authenticity and identity." Current Issues in Tourism 11(4): 349-367.

Chaney, R. (2017). "“Heritage" as alternative place and space: old-time music and roots- and routes-based tourism in Southern Appalachia." Journal of Heritage Tourism 12(2): 125-138.

Chen, S. C. (2011). "Residents' Perceptions of the Impact of Major Annual Tourism Events in Macao: Cluster Analysis." Journal of Convention \& Event Tourism 12(2): 106-128.

Connell, J. and C. Gibson (2004). "World music: deterritorializing place and identity." Progress in Human Geography 28(3): 342-361. 
Diettrich, B. (2015). "Performing arts as cultural heritage in the Federated States of Micronesia." International Journal of Heritage Studies 21(7): 660-673.

Ernest, L. and Heriyadi (2008). Basic analysis: A guide for student and researchers. Lee Miing Press Sdn Bhd, Kuching Srawak.

Fremaux, S. and M. Fremaux (2013). "Remembering the Beatles 'legacy in Hamburg's problematic tourism strategy." Journal of Heritage Tourism 8(4): 303-319.

Garrido, M. (2011). "Home is Another Country: Ethnic Identification in Philippine Homeland Tours." Qualitative Sociology 34: 177-199.

Goulding, C. and D. Domic (2009). "Heritage, Identity and Ideological Manipulation: The Case of Croatia." Annals of Tourism Research 36(1): 85-102.

Gross, M. J. and G. Brown (2006). "Tourism experiences in a lifestyle destination setting: The roles of involvement and place attachment." Journal of Business Research 59: 696-700.

Gross, M. J. and G. Brown (2008). "An empirical structural model of tourists and places: Progressing involvement and place attachment into tourism." Tourism Management 29: 1141-1151.

Hair, J. F., et al. (2010). Multivariate Data Analysis. New York, Pearson Education, Inc.

Henke, L. L. (2005). "Music Induced Tourism: Strategic Use of Indigenous Music as a Tourist Icon." Journal of Hospitality \& Leisure Marketing 13(2): 3-18.

Hibbert, J. F., et al. (2013). "Understanding the influence of interpersonal relationships on identity and tourism travel." Anatolia 24(1): 30-39.

Hoeven, A. v. d. (2012). "The popular music heritage of the Dutch pirates: illegal radio and cultural identity." Media, Culture \& Society 34(8): 927-943.

Hoeven, V. d. and A. Brandellero (2015). "Places of popular music heritage: The local framing of a global cultural form in Dutch museums and archives." POETICS: Journal of Empirical Research on Culture, the Media and the Arts 51: 37-53.

Huh, J., et al. (2006). "Cultural/Heritage Destinations: Tourist Satisfaction and Market Segmentation." Journal of Hospitality \& Leisure Marketing 14(3): 81-99.

Hwang, S.-N., et al. (2005). "The relationship among tourists' involvement, place attachment and interpretation satisfaction in Taiwan's national parks." Tourism Management 26: 143-156. 
Io, M.-U. (2018). "Collaboration between practitioners and public agencies in preserving and promoting musical heritage in Macao." Journal of Heritage Tourism: 1-14.

Io, M.-U. (2019). "Understanding the core attractiveness of performing arts heritage to international tourists " Tourism Geographies: 1-19.

Jobst, J. and S. Boerner (2011). "Understanding customer satisfaction in opera: first steps toward a model." International Journal of Nonprofit and Voluntary Sector Marketing 16(1): 50-69.

Kil, N., et al. (2012). "Place attachment as a mediator of the relationship between nature-based recreation benefits and future visit intentions." Journal of Sustainable Tourism 20(4): 603-626.

Kim, S., et al. (2018). "Intra-Asian performing arts tourism - the motivations, intentions, and performance preferences of Japanese visitors." Tourism Recreation Research 43(3): 372-388.

Kruger, M. and M. Saayman (2018). "'All that jazz': the relationship between music festival visitors' motives and behavioural intentions." Current Issues in Tourism: 1-16.

Lee, K. H. and D. T.-K. Wong (2017). "Chinese popular music as a musical heritage and cultural marker of the Malaysian Chinese." International Journal of Heritage Studies 23(10): 989-1001.

Lee, Y.-g., et al. (2016). "The Extended Marketing Mix in The Context of Dance as a Performing Art." Social Behavior and Personality 44: 1043-1056.

Li, J. (2012). "The folkloric, the spectacular, and the institutionalized: touristifying ethnic minority dances on China's southwest frontiers." Journal of Tourism and Cultural Change 10(1): 65-83.

Lim, C. C. and L. J. Bendle (2012). "Arts tourism in Seoul: tourist-orientated performing arts as a sustainable niche market." Journal of Sustainable Tourism 20(5): 667-682.

Lin, M. and E. Dong (2018). "Place construction and public space: Cantonese opera as leisure in the urban parks of Guangzhou, China." Leisure Studies 37(2): 117-131.

Macao Government Tourist Office (2017). "Calendar of Events. Retrieved on 22th August 2017, from http://en.macaotourism.gov.mo/events/calendar.php."

Macau Cultural Affairs Bureau (2016). The Enchanting Red Boat - An episode of the cantonese opera culture, Cultural Affairs Bureau of the Macao S.A.R.

Maruyama, N., et al. (2010). "Negotiating Identity: Experiences of "Visiting Home" among Chinese Americans." Tourism, Culture and Communication 10: 1 - 14. 
Matheson, C. M. (2008). "Music, Emotion and Authenticity: A Study of Celtic Music Festival Consumers." Journal of Tourism and Cultural Change 6(1): 57-74.

McClinchey, K. A. (2008). "Urban Ethnic Festivals, Neighborhoods, and The Multiple Realities of Marketing Place." Journal of Travel \& Tourism Marketing 25(3-4): 251-264.

Miichi, K. (2016). "Playful Relief Folk Performing Arts in Japan after the 2011 Tsunami." Asian Ethnology 75(1): 139-162.

Palma, L., et al. (2017). "Live Flamenco in Spain: A Dynamic Analysis of Supply, With Managerial Implications." International Journal of Art Management 19(3): 58-70.

Park, H. y. (2011). "SHARED NATIONAL MEMORY AS INTANGIBLE HERITAGE: Re-imagining Two Koreas as One Nation." Annals of Tourism Research 38(2): 520-539.

Patkin, T. T. (2015). "These are a few of my favorite things: The search for authenticity in Sound of Music tourism." Tourism, Culture \& Communication 15: 69-85.

Pavluković, V., et al. (2017). "Social impacts of music festivals: Does culture impact locals' attitude toward events in Serbia and Hungary?" Tourism Management 63: 42-53.

Ramkissoon, H., et al. (2013). "Testing the dimensionality of place attachment and its relationships with place satisfaction and pro-environmental behaviours: A structural equation modelling approach." Tourism Management 36: $552-566$.

Rojas, C. d. and C. Camarero (2008). "Visitors' experience, mood and satisfaction in a heritage context: Evidence from an interpretation center." Tourism Management 29: 525-537.

Roth, M. S. and B. Romeo (1992). "Matching Product Catgeory and Country Image Perceptions: A Framework for Managing Country-of-Origin Effects." Journal of International Business Studies 233(477-497).

Santa-Cruz, T. L.-G. F. G. (2016). "International tourism and the UNESCO category of intangible cultural heritage " International Journal of Culture, Tourism and Hospitality Research 10(3): 310-322.

Schofield, P. and K. Thompson (2007). "Visitor Motivation, Satisfaction and Behavioural Intention: The 2005 Naadam Festival, Ulaanbaatar." International Journal of Tourism Research 9: 329-344.

Schumacker, R. E. and R. G. Lomax (2004). A beginner's guide to structural equation modeling. Mahwah, NJ, Lawrence Erlbaum Associates. 
Song, H. and C. Cheung (2010). "Factors affecting tourist satisfaction with theatrical performances: a case study of the romance of the song dynasty in Hangzhou, China." Journal of Travel \& Tourism Marketing 27(7): 708-722.

Soper, A. K. (2007). "Developing Mauritianness: National Identity, Cultural Heritage Values and Tourism." Journal of Heritage Tourism 2(2): 94-109.

Statistics and Census Bureau (2016). "Population Census, Retrieved on February 10, 2017, from http://www.dsec.gov.mo/Statistic.aspx?lang=en-US\&NodeGuid=ee77eb29-fd1b-4f13-8a2d-3181e93adb05."

Tikkanen, I. (2008). "Internationalization Process of a Music Festival: Case Kuhmo Chamber Music Festival." Joumal of Euromarketing 17(2): 127-139.

UNESCO (2003). "Text of the Convention for the Safeguarding of the Intangible Cultural Heritage. Retrieved March 21, 2017, from http://www.unesco.org/culture/ich/en/convention\#art2 ".

UNESCO (2009). "Yueju opera, Retrieved February 10, 2017, from

http://www.unesco.org/culture/ich/en/RL/yueju-opera-00203."

Vinnicombe, T. and P. U. J. Sou (2017). "Socialization or genre appreciation: the motives of music festival participants." International Journal of Event and Festival Management 8(3): 274-291.

Voss, K. E., et al. (2003). "Measuring the Hedonic and Utilitarian Dimensions of Consumer Attitude." Journal of Marketing Research 40(3): 310-320.

World population review (2020). "Macao population." Retrieved February 19, 2020, , from http://worldpopulationreview.com/countries/macau-population/.

Wu, J., et al. (2019). "Determinants of demand for traditional Chinese opera." Empirical Economics 57(6): 21292148.

Xie, P. F., et al. (2007). "Gazing the hood: Hip-Hop as tourism attraction." Tourism Management 28: 452-460.

Yi, L. and F. Colbert (2018). "Chinese Opera and the International Market." International Journal of Arts Management 20(3): 75-82.

Zhang, C. X., et al. (2019). "National identity and cultural festivals in postcolonial destinations." Tourism Management 73: 94-104.

Zhang, J. (2010). Macau Opera. Beijing, China, Culture and Art Publishing House. 
Zhao, S. and D. J. Timothy (2017). "Tourists' consumption and perceptions of red heritage." Annals of Tourism Research 63(97-111).

Zheng, D., et al. (2019). "Emotional responses toward Tourism Performing Arts Development: A comparison of urban and rural residents in China." Tourism Management 70: 238-249. 